\title{
A CONSTRUÇÃO DA PROFISSIONALIDADE DOCENTE NO ESTÁGIO SUPERVISIONADO
}

\author{
THE CONSTRUCTION OF THE TEACHER PROFESSIONALITY ALONG THE \\ SUPERVISED INTERNSHIP \\ LA CONSTRUCCIÓN DE PROFESIONALIDAD DOCENTE EN PRÁCTICAS \\ SUPERVISADAS
}

Nair Pires

Universidade Federal de Minas Gerais - UFMG

E-mail: nair.pires@yahoo.com.br

\begin{abstract}
RESUMO
Este artigo tem como objetivo refletir sobre o Projeto Didático, fruto da experiência desenvolvida no âmbito do estágio supervisionado do curso de Licenciatura em Música, da Universidade Federal de Ouro Preto (UFOP), no primeiro semestre do ano de 2019. O Projeto tomou como referencial teórico a profissionalidade docente, entendida como aquilo que é específico na ação docente e que se constrói a partir da experiência e da prática no campo de trabalho, apoiada em saberes teóricos, práticos e da reflexão ética. Desenvolvido ao longo de um semestre letivo, o Projeto se estruturou em 04 etapas, articuladas entre si: 1-Preparação; 2- Interação com a escola (observação da escola e da sala de aula); 3- Intervenções (planejamento, realização, avaliação); 4- avaliação (seminários, relatório final). As Pautas Didáticas foram elaboradas com o objetivo de proporcionar aos futuros professores maior compreensão do fenômeno educativo a partir de processos de observação, reflexão, problematização, elaboração e realização de práticas de ensino. O Projeto Didático apoiado nas Pautas Didáticas potencializou o processo de reflexão sobre a organização da gestão da classe e gestão dos aprendizados no processo de ensino e de aprendizagem.
\end{abstract}

PALAVRAS-CHAVE: Profissionalidade docente. Formação de professor. Estágio supervisionado.

\begin{abstract}
This article aims to reflect on the Didactic Project, as a result of the experience developed within the supervised internship scope of the Degree in Music, in Federal University of Ouro Preto (UFOP), during the first semester/2019. The Project took teacher professionality as a theoretical reference, understood as the specific teaching action constructed from the experience and the practice in the working field, supported on theoretical and practical knowledge and the ethical reflection. Developed over college semester, the Project was structured on 04 stages, articulated with each other: 1 - Preparation; 2 - Interaction with the school (school and classroom under observation); 3 - Interventions (planning, accomplishment, appraisal); 4 - Assessment (seminars, final report). Didactic Guidelines were made in order to provide to future teachers a better understanding of the educational phenomenon from observation, reflection, questioning, elaboration and accomplishment of teaching practices processes. The Didactic Project supported by the Didactic Guidelines enhanced the process of reflection on the organization of class management and learning management in the teaching and leanrning process.
\end{abstract}

KEYWORDS: Teacher professionality. Teacher training. Supervised internship.

\section{RESUMEN}

Este artículo tiene como objetivo reflexionar sobre el Proyecto Didáctico, resultado de la experiencia desarrollada en el ámbito de la pasantía supervisada del curso de Licenciatura en Música, desde XXXX, en el primer semestre de 2019. El Proyecto tomó la profesionalidad docente como referencia teórica, entendida como lo que es especifico en la acción docente y que se construye a partir de la experiencia y la práctica en el campo de trabajo, respaldado por los conocimientos teóricos, prácticos y por la reflexión ética. Desarrollado durante un semestre académico, el Proyecto se estructuró en 04 etapas, articuladas entre sí: 1-Preparación; 2- Interacción con la escuela (observación de la escuela y el aula); 3- Intervenciones (planificación, implementación, 
evaluación); 4- evaluación (seminarios, informe final). Los instrumentos didácticos se desarrollaron con el objetivo de proporcionar a los futuros docentes una mejor comprensión del fenómeno educativo basado en procesos de observación, reflexión, problematización, elaboración y realización de prácticas docentes. El Proyecto apoyado por los Instrumentos Didácticos fortaleció el proceso de reflexión sobre la organización de la gestión de clase y la gestión del aprendizaje en el proceso de enseñanza y aprendizaje.

PALABRAS-CLAVE: Profesionalidad docente. Formación del profesorado. Prácticas supervisadas.

\section{INTRODUÇÃO}

Este artigo tem como objetivo refletir sobre o Projeto Didático, fruto da experiência desenvolvida no âmbito do estágio supervisionado do curso de Licenciatura em Música, da Universidade Federal de Ouro Preto (UFOP), no primeiro semestre do ano de 2019. A experiência como professora do estágio supervisionado, ao longo de 15 anos, me fez refletir sobre a necessidade de potencializar a formação profissional do professor de música para o ensino em escolas de educação básica. Apesar de este curso ter alguns espaços de interlocução com escolas de educação básica - projetos de extensão e o Programa Institucional de Bolsas de Iniciação à Docência (Pibid) - o estágio supervisionado configura-se, por excelência, espaço de aprendizagem da docência.

No estágio supervisionado, a formação docente se dá por meio da interação com a cultura escolar e com os professores em ação, da observação, análise, organização, realização e reflexão de práticas de ensino de música, orientadas por professores da universidade e da escola de educação básica. Apesar de haver atividades de observação do espaço escolar e da sala de aula, os licenciandos apresentam dificuldade de problematizar e relacionar a estrutura ao funcionamento da escola, ou o projeto pedagógico da escola às propostas de ensino de música. Isso porque, existem crenças cristalizadas de que: o ensino de música é uma prática externa e desvinculada da cultura escolar; ensinar música é ensinar tocar um instrumento ou ensinar parâmetros do som - duração, altura, timbre, intensidade; para ensinar música basta saber música; aula de música é improvisação pedagógica; os elementos da linguagem musical são os únicos conteúdos a serem ensinados na aula de música em escolas de educação básica.

Além disso, a maioria dos licenciandos nunca elaborou um plano de aula, ordenou atividades do simples para o complexo, elegeu estratégias de gestão da classe e gestão dos aprendizados, ou construiu atividades de avaliação e de fixação dos aprendizados. Ou seja, há um desconhecimento dos conteúdos da didática geral que podem subsidiar a construção fundamentada de processos de ensino e de aprendizagem. Ensinar música parece ser uma atividade sem saberes pedagógicos, em que a prática é pensada somente pelo ensino do 
conteúdo musical, com alguma metodologia e sem tecnologia própria. Algumas pesquisas reafirmam essa questão, quando apontam as dificuldades dos licenciandos na operacionalização do ensino: planejamento das aulas, ordenação das tarefas, ações e procedimentos didáticos, seleção dos conteúdos, formas de organização do ensino e das aprendizagens dos alunos. (DELBEN, 2011; SILVA, 2013; NARITA, 2015; PIRES, 2015a, 2015b).

Além da ausência da formação geral em didática, o currículo de formação profissional desse curso também prescinde da oferta da didática específica da Música. Do ponto de vista pedagógico, o currículo se limita à oferta de disciplinas de Metodologia da Educação Musical (I e II), com 30 horas cada uma, com foco nas contribuições pedagógicas de autores da área de música, a exemplo de Dalcroze, Orff, Willems, Schafer, Self, Paynter, Swanwick, dentre outros. De fato, o conhecimento metodológico é importante para conhecer propostas pedagógicas produzidas em contextos e momentos históricos distintos, compreender diferentes concepções e abordagens de ensino de música. Porém, esse conhecimento não pode ser tomado como estático para subsidiar práticas a serem replicadas nos diferentes espaços sociais. Ao contrário, o conhecimento metodológico precisa ser transformado e utilizado como matéria-prima para a construção de práticas situadas de ensino de música.

Isso mostra que o conhecimento metodológico, per si, não garante ao professor a expertise necessária para organizar o ensino música, seja nos momentos de planejamento, interação ou de avaliação dos aprendizados. Na organização do ensino, o professor precisa mobilizar diferentes conhecimentos que o ajude a tomar decisões éticas, políticas e pedagógicas, considerando-se: a cultura escolar e o projeto pedagógico; a faixa etária das crianças, seus conhecimentos, expectativas e interesses; a finalidade educativa da música na formação geral do aluno, em cada etapa da educação básica; o conteúdo musical pertinente aos conteúdos escolares em construção; aspectos da didática geral e específica. O amálgama desses conhecimentos se transforma em um outro conhecimento, o curricular, que permite organizar propostas curriculares situadas de ensino de música.

Em pesquisa recente sobre a profissionalidade emergente dos licenciandos participantes do Pibid Música, Pires (2015a), apoiada nos estudos de Del-Ben (2011), aponta a presença de diferentes formas de organização do ensino de música em escolas de educação básica - por conteúdos, por assunto, por atividades e por projetos temáticos. Os resultados desta pesquisa apontam os projetos temáticos como um conhecimento curricular que permite selecionar e organizar o conteúdo a ser ensinado, preparando-o em função das particularidades dos 
contextos escolares, das características socioculturais dos alunos, dos diferentes níveis de ensino e dos objetivos da ação educativa. Além disso, a mesma pesquisa reforça a ideia da necessidade de reflexão sobre as práticas observadas e desenvolvidas, como forma de construção do conhecimento profissional e da profissionalidade docente, e aponta o conhecimento ético da realidade em que se vive como fundamental ao repertório de conhecimentos profissionais do professor de música.

Como observa Nóvoa (2002), construir e reconstruir o conhecimento profissional pressupõe uma reflexão prática e deliberativa, um espaço de discussão em que as práticas e as opiniões singulares adquiram visibilidade e sejam submetidas à opinião dos outros. Daí a ideia do "saber analisar e saber analisar-se" como sendo um dilema do conhecimento, o que significa admitir a impossibilidade de que ele não se construa a partir da reflexão sobre a prática. Com base nos achados da pesquisa de Pires (2015a) e tomando a profissionalidade como eixo da formação docente, foi desenvolvido o Projeto Didático com o objetivo de potencializar a construção da profissionalidade dos estagiários em música, considerando-se as dimensões teórica, prática e da reflexão ética.

\section{A PROFISSIONALIDADE COMO EIXO DA FORMAÇÃO DOCENTE}

A formação profissional do professor se constrói mediante o contato com experiências diversificadas que compõem e fundamentam a prática pedagógica. Tornar-se professor, desde a formação inicial, requer a constante reflexão sobre o que se faz, como se faz e por que se faz como se faz na prática pedagógica na sala de aula. Essa aprendizagem docente relaciona-se com a construção da profissionalidade docente, que pode ser entendida como aquilo que é específico na ação docente, isto é, o conjunto de comportamentos, conhecimentos, destrezas, atitudes e valores que constituem a especificidade de ser professor. (SACRISTÁN, 1995, p. 64). Segundo esse autor, o debate sobre a profissionalidade passa pela discussão sobre os fins e as práticas do sistema escolar, o que remete a um tipo de conhecimento e desempenho específicos da profissão docente.

A profissionalidade é concebida como algo que se constitui de maneira processual e que está em permanente elaboração, e sua análise, portanto, se dá de acordo com o contexto em que encerra. $\mathrm{O}$ conjunto de aspectos relacionados a valores, currículos, práticas metodológicas e avaliação configura o que Sacristán (1995) chama de profissionalidade ideal. Ancorada a um 
pensamento pragmático, a profissionalidade relaciona ideias, intenções e ações à avaliação das condições de aplicação. Ou seja, ela desempenha a função de aplicar princípios gerais a situações particulares que se relacionam com a atividade desenvolvida. Assim, a profissionalidade pode ser designada como tudo o que foi adquirido pela pessoa como experiência e saber, sua capacidade de utilizá-la em uma situação dada e seu modo de cumprir as tarefas.

De caráter instável e processual, a profissionalidade se constitui no próprio ato do trabalho e requer adaptação a um contexto em movimento e aprendizagem permanente e coletiva de novos saberes. É por meio da profissionalidade que o professor adquire as competências necessárias ao desempenho de suas atividades docentes e os saberes próprios de sua profissão. Portanto, ela está intimamente ligada aos componentes dos processos de apropriação da base de conhecimentos da docência como profissão, tais como: saberes, competências, pesquisa, reflexão, crítica epistemológica, aperfeiçoamento, capacitação, inovação, criatividade, pesquisa, entre outros. (NÚÑEZ; RAMALHO, 2008, p. 4).

Apesar de ser um conceito polissêmico, um princípio geral considerado por todos os autores é pensar a profissionalidade como

\footnotetext{
processo de constituição das características específicas da profissão - como aquisição dos conhecimentos necessários ao desempenho de suas atividades, assimilação de saberes pedagógicos, desenvolvimento de atitudes, valores, habilidades e/ou competências para aperfeiçoar o exercício docente... (GORZONI; DAVIS, 2017, p. 1406).
}

Nesse sentido, a profissionalidade se constrói a partir da experiência e da prática no campo de trabalho, apoiada em saberes teóricos (saber), saberes da ação (saber-fazer) e saberes sobre a reflexão ética (saber-ser). O processo de construção da profissionalidade requer a presença de mediadores no processo de ensino e de aprendizagem, que facilitem a tomada de consciência e colaborem com a análise e organização de práticas de ensino. Portanto, a forma de organização do ensino no estágio supervisionado e as estratégias didáticas utilizadas são fundamentais para potencializar a construção de conhecimentos profissionais dos futuros professores. 
O estágio supervisionado no curso de Música da UFOP tem carga horária total de 405 horas, distribuídas em quatro semestres $(90,105,105,105)$, com início no 50 período do curso. Para esse artigo, vou me limitar ao trabalho desenvolvido no Estágio Supervisionado A, no $5^{\circ}$ período do curso de Licenciatura em Música, no primeiro semestre do ano de 2019. Com uma turma de 19 alunos, a experiência teve duração de 18 semanas e carga horária de 90 horas. Os licenciandos, agrupados em duplas ou trios, desenvolveram atividades em escolas de educação básica nas esferas municipal, estadual e federal, da cidade de Ouro Preto (MG). A carga horária semestral de 90 horas foi distribuída em 30 horas presenciais, com a professora coordenadora da universidade; 40 horas no espaço escolar, junto ao professor(a) supervisor(a) da escola de educação básica; 10 horas para análise e organização dos dados; 10 horas para confecção de relatório, estudos teóricos, preenchimento das Pautas didáticas (conjunto de instrumentos construídos no âmbito do pós-doutorado, realizado na Université Laval (CA), sob a supervisão do professor Clermont Gauthier).

As Pautas didáticas foram elaboradas com o objetivo de proporcionar aos futuros professores maior compreensão do fenômeno educativo (impasses, desafios, possibilidades, formas de ser e de estar na profissão) a partir da observação, de processos de reflexão (antes, durante e depois da ação pedagógica), da problematização, elaboração e realização de práticas de ensino. Ou seja, é um conjunto de instrumentos que possibilita aos alunos ultrapassar "os limites do senso comum pedagógico e do meramente observável”. (PIMENTA; LIMA, 2008, p. 103). Nesse sentido, surge a possibilidade de construir alternativas didáticas mais contextualizadas, por meio de pistas que emergem do processo de reflexão dos dados coletados.

O Projeto Didático foi idealizado como estratégia formativa para potencializar a construção da profissionalidade docente, nas suas dimensões teórica, prática e ética. A dimensão teórica tem como objetivo iluminar a apropriação da realidade escolar, para analisála e questioná-la criticamente; subsidiar a reflexão de ações práticas do professor da escola de educação básica e aquelas desenvolvidas pelos licenciandos. A dimensão prática é o momento do desenvolvimento de ações planejadas no campo de trabalho articulado aos conhecimentos teóricos (saber-fazer). A dimensão ética enfatiza questões, opções, dilemas e dúvidas que surgem sobre o caráter problemático das situações do campo de trabalho, estimulando nos sujeitos a reflexão e as decisões deliberadas. Essa dimensão se relaciona, portanto, ao 
desenvolvimento da compreensão da prática pedagógica, por meio da observação, diagnósticos da realidade, do raciocínio sobre a ação e para a ação (saber-ser).

Desenvolvido ao longo de um semestre letivo, o Projeto Didático se estruturou em 04 fases, articuladas entre si: 1-Preparação; 2- Interação com a escola (observação da escola e da sala de aula); 3- Intervenções (planejamento, realização, avaliação); 4- avaliação (seminários, relatório final).

\section{Preparação}

A etapa de Preparação tem como finalidade apresentar aos licenciandos a estrutura, objetivos, cronograma de trabalho e as formas de avaliação do processo de estágio; institucionalizar as relações entre universidade e escolas de educação básica por meio de documentação própria; explicitar os sujeitos do processo de formação docente - licenciando mediado pelo professor universitário e professor supervisor da escola de educação básica - e o papel a ser desempenhado por cada um deles, ao longo do estágio supervisionado; distribuir os licenciandos em pequenos grupos de estágio.

Nessa etapa é que se dá o primeiro contato dos licenciandos com o cenário profissional real, e isso requer planejamento cuidadoso das ações a serem desenvolvidas. Ao chegar ao campo profissional, é necessário mobilizar posturas, habilidades, comportamentos, atitudes e saberes para a obtenção do aceite da instituição escolar, que se configuram conteúdos requeridos da profissionalidade docente. A dimensão teórica desse conteúdo pode ser trabalhada a partir de temas sobre a profissionalidade docente e sua importância para a profissionalização do ensino; o estágio como lócus de aprendizado da docência e sua centralidade no processo de formação profissional do professor de música; a ética profissional e o estar na profissão docente. Como afirmam Oliveira e Kikuchi (2018, p. 811), "leituras e atividades que propiciam a reflexão levam os licenciandos a mudarem suas concepções ao longo do tempo".

Junto ao embasamento teórico, a dimensão ética é abordada, explicitamente, a partir de reflexões e análises de valores, comportamentos, atitudes e posturas adequadas (ou não) ao bom convívio socioprofissional. Assim como Farias et al. (2011, p. 88), entendemos que a dimensão ética tem um conteúdo que é cultural, que se traduz em formas de agir, de se comportar, de estar no mundo. Portanto, existem formas de se relacionar com os outros que se dão de acordo com cada cultura e momento histórico. Para abordar a dimensão ética, foi construída a Pauta 
de formação da ética profissional, um instrumento didático que permite a discussão, análise e reflexão de valores, comportamentos, atitudes, posturas; de formas de ser e de agir profissionalmente. A cada aula, um novo conteúdo da dimensão ética da profissionalidade pode ser trabalhado por meio de: reflexões em pequenos ou grandes grupos; análises de fragmentos de filmes, textos ou de relatos pessoais; de situações descritas no diário de campo. A Pauta de formação da ética profissional contém uma coluna para o conteúdo ético da profissionalidade docente (valor, comportamento, atitude ou postura), uma coluna para registro de significados desse conteúdo, e outra coluna para registro de exemplos e contraexemplos de formas de agir do professor e do aluno no espaço escolar em relação ao conteúdo selecionado.

A avaliação da primeira etapa é feita por meio da Pauta de autoavaliação dos aprendizados, que apresenta síntese do processo vivenciado e, em seguida, solicita aos alunos uma narrativa do que reconhecem como aprendizados adquiridos. Somente ao trazer à consciência os aprendizados - impressões, dificuldades e formas de lidar com elas, reflexões sobre comportamentos, valores, atitudes e posturas - é que se inicia o processo de construção dos conhecimentos profissionais. Os aprendizados reconhecidos são, posteriormente, socializados e discutidos, como forma de significar as experiências vividas, estimulando a construção da profissionalidade docente.

\section{Interação com a Escola}

A Interação com a escola campo de estágio é a etapa em que o licenciando tem contato com os professores em ação, em um espaço real de trabalho, com suas complexidades, dilemas e singularidades. Esse é o momento do "encontro", em que "os estudantes saem das aulas [universitárias] para se encontrar com a realidade viva de um cenário profissional [...] real, e conhecer e participar in situ da cultura e estilo de trabalho daqueles que exercem a profissão..." (ZABALZA, 2014, p. 116). É o encontro com o outro (outros colegas, professores, profissionais da educação, alunos, pais); com a instituição escolar (estrutura, funcionamento, currículo, cultura); consigo mesmo (capacidade de enfrentar frustações, de envolver-se pessoalmente, de identificar pontos fortes e fracos); com a ética da profissão professor (individual e coletiva). Daí o caráter interativo dessa etapa, pois exige o encontro com o outro, sua participação e seu consentimento. 


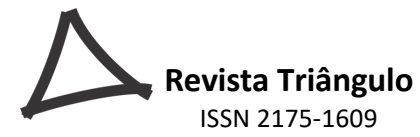

O encontro com a instituição campo de estágio permite desenvolver o olhar crítico sobre os acontecimentos do cotidiano escolar, tanto do ponto de vista macro, a escola, quanto do micro, a sala de aula. Assim, essa etapa se divide em duas fases, tendo como instrumento de coleta de dados, a observação não participante. Primeiro, por meio da Pauta de observação da escola, são realizadas 10 horas de observação da instituição escolar, buscando identificar, relacionar e problematizar elementos da estrutura (física, material, recursos humanos, condições do ambiente), do funcionamento (rotinas e regras), e do projeto pedagógico (arte no currículo, relações interpessoais).

Após a coleta, os dados são analisados à luz de questões norteadoras como: de que maneira a estrutura interfere no funcionamento, e vice-versa? Que lugar a arte ou a música ocupa na cultura escolar e no projeto pedagógico? Que elementos caracterizam a cultura escolar? Ao longo dessa etapa, leituras e reflexões teóricas subsidiam a coleta e análise dos dados, nos momentos presencias na universidade. A dimensão ética também é abordada por meio de atividades como: identificar e descrever uma situação observada e apresentar análise crítica com base em valores, comportamentos, atitudes ou posturas adotadas.

$\mathrm{Na}$ segunda fase dessa etapa, os licenciandos realizam 20 horas de observação do trabalho docente, em sala de aula. De acordo vários autores, ao desempenhar a principal atividade docente - o ensino - os professores desempenham duas funções articuladas e complementares: gestão da classe e gestão dos aprendizados (SHULMAN, 1986; TARDIF, 2011; ALTET, 2012; GAUTHIER et al, 2013; GAUTHIER; BISSONNETTE; RICHARD, 2013). Nesse sentido, o exercício da prática docente consiste justamente em fazer convergir essas duas funções da melhor maneira possível, uma vez que elas se constituem as dimensões centrais da profissão professor (GAUTHIER at al., 2013, p. 345). A gestão da classe diz respeito a um conjunto de regras e disposições necessárias à manutenção de um ambiente favorável ao ensino e ao aprendizado dos alunos, que se define em relação às variáveis do contexto de trabalho (atividades, tempo disponível, organização material e social, desenvolvimento intelectual e social dos alunos, influências culturais e socioeconômicas). A gestão dos aprendizados engloba o conjunto de operações que o professor utiliza para fazer aprender aos alunos o conteúdo de ensino (planejamento, estratégias de interação com os alunos e de avaliação dos aprendizados).

Com base nas duas funções pedagógicas da atividade de ensino, a coleta de dados é feita por meio da Pauta de observação da sala de aula, instrumento didático que foca elementos da 
gestão da classe (características do espaço, regras de funcionamento e formas de interação) e da gestão dos aprendizados (estratégias didáticas utilizadas na abertura, desenvolvimento e fechamento da aula). Como salienta Altet (2012, p. 54), os instrumentos de análise e reflexão de práticas permitem construir a profissionalidade docente pelo desenvolvimento de "uma metacompetência: o saber analisar”. A partir deles, é possível ler práticas e situações, explicitar saberes da prática e formalizar saberes sobre a prática.

Em se tratando da gestão da classe, os licenciandos são despertados a identificar, por exemplo, estratégias didáticas utilizadas para despertar o interesse e motivar os alunos; formas de solucionar um conflito ou de expor a matéria, fixar e avaliar os aprendizados; maneiras de organizar o ambiente da sala de aula, de se comunicar com os alunos, de estabelecer acordos e regras. Quanto à gestão da sala de aula, são analisadas estratégias didáticas utilizadas na abertura da aula (objetivos de aprendizagem e sua relação com os conhecimentos prévios dos alunos), no desenvolvimento (tipos de atividades e sequenciamento, organização do tempo em relação ao objetivo de ensino, materiais didáticos, formas de avaliação), e no fechamento (deveres, estratégias de fixação). Ao desempenhar essas duas funções pedagógicas, aspectos éticos como respeito, compromisso, envolvimento e seriedade interferem positivamente na relação pedagógica, o que contribui para a construção de uma relação de confiança e de valorização da ação educativa. A postura do professor, a forma como ele se relaciona com o conhecimento e com os alunos interfere em todo o processo pedagógico. Numa palavra, "a relação ética com o conhecimento gera interesse, disposição para aprender, participação e envolvimento". (PIRES, 2015b, p.58). E a compreensão crítica da relação ética do professor com os alunos e com o conhecimento é fundamental à formação dessa dimensão da profissionalidade docente.

Os dados coletados são registrados no diário de campo e cada grupo analisa, sistematiza e divulga, publicamente, os resultados. No momento de socialização dos resultados, o grupo destaca estratégias, problematizações e hipóteses que apontem pistas para a proposta de intervenção didática. Ao compartilhar as experiências, fica evidente a singularidade dos contextos escolares, das práticas pedagógicas, das formas de agir e de estar na profissão professor. Entretanto, apesar da incerteza e da complexidade do trabalho docente, é possível identificar uma estrutura de base dotada de certa estabilidade. Nem tudo é contingência na atividade de ensino, existe um contexto geral que se repete e que precisa ser compreendido naquilo que possui de generalidade. De certa forma, aquilo que escapa ao contingente é 
exatamente "o que tende a ser identificado e analisado por um repertório de conhecimentos". (GAUTHIER et al., 2013, p. 293).

Como finalização dessa etapa, os licenciandos preenchem a Pauta de autoavaliação dos aprendizados, registrando o que eles reconhecem como aprendizado adquirido ao longo da etapa de Interação com a escola (seja teórico, prático e/ou ético).

\section{Intervenção Didática}

A etapa da Intervenção Didática é o momento em que o licenciando - a partir dos conhecimentos prévios sobre a escola e seu projeto pedagógico, o ambiente da sala de aula e os conteúdos trabalhados pelo professor regente, os alunos e suas características, a rotina e a cultura escolar, as finalidades educativas do ensino de música e as dificuldades e possibilidades de atuação - planeja, executa e reflete, criticamente, sobre o processo de ensino. Para essa etapa, são reservadas 10 horas e o número de intervenções é, previamente, acordado com o professor supervisor, de acordo com as possibilidades do contexto escolar.

Para a organização da proposta de ensino de música foi construído um referencial teórico que considera: 1- a adoção do trabalho por projetos de ensino como alternativa possível à prática musical nas escolas de educação básica (PIRES, 2015a; DEL-BEN, 2011); 2- a composição, apreciação e performance (cotejadas pela literatura e a técnica) como as principais atividades para o ensino e aprendizagem da música (SWANWICK, 1979); 3- a abordagem de diferentes tipos de conteúdos, a partir de um tema fio condutor - procedimentais, factuais, conceituais e atitudinais (ZABALA, 2010); 4- a organização da gestão da classe e da gestão dos aprendizados nos momentos de planejamento, interação e avaliação dos aprendizados (GAUTHIER; BISSONNETTE; RICHARD, 2013).

A perspectiva teórica adotada permite reflexões e (des)construções de crenças como: o ensino de música é ensino do instrumento (a atividade de performance ou o conteúdo procedimental configura-se uma possibilidade de abordagem); o ensino de música é uma coletânea de atividades "criativas", desconectadas e sem objetivo educativo claro (as atividades são escolhidas a partir dos objetivos de ensino e sequenciadas do simples para o complexo); o ensino de música é uma prática improvisada (a necessidade de organização da gestão da classe e da gestão dos aprendizados em função da aprendizagem requerida); os parâmetros sonoros 
como conteúdo privilegiado do ensino de música (os conteúdos são amplos, contextualizados e emergem do tema, fio condutor).

O projeto de ensino de música é estruturado em torno de três ou mais aulas, dependendo do acordo com o professor supervisor. O planejamento inicia-se com a escolha do tema, fio condutor, considerando-se os dados coletados na fase anterior - conhecimentos prévios e interesse dos alunos, necessidades educativas e/ou sugestões apontadas pelo professor da escola. Após a escolha do tema, é feito o exercício de identificação dos conteúdos de aprendizagem implícitos no tema e dos produtos a serem desenvolvidos (sonorização de uma história, arranjo, teatro musical, construção de instrumentos, apresentação musical de uma partitura gráfica, dentre outros). Em função disso, as atividades de aprendizagem são definidas, ordenadas do simples para o complexo e distribuídas ao longo das aulas previstas. Relacionadas a elas, são elaboradas as estratégias de ensino e os materiais didáticos necessários à aprendizagem musical. Para subsidiar o processo de planejamento, a Pauta de Planejamento do Projeto de Intervenção Didática é disponibilizada aos licenciandos, com o objetivo de orientá-los no "passo a passo" da organização da prática pedagógica.

$\mathrm{Na}$ fase de realização do projeto de ensino de música, o planejamento, por seu caráter flexível, passa por ajustes realizados com o apoio do professor orientador e do supervisor. A cada aula ministrada, os licenciandos são motivados a refletir sobre a relação entre a ação planejada e a ação executada, tendo o diário de campo como lugar de registro de todo o processo de ensino e de aprendizagem: o que eu fiz, como eu fiz, por que eu fiz como eu fiz, como eu me senti fazendo o que eu fiz (emoções, sentimentos, angústias, dilemas, dificuldades, dúvidas, acertos, percepções).

$\mathrm{Na}$ fase de avaliação final, os licenciandos elaboram um texto sobre a experiência de planejar e executar projetos de ensino música em escolas de educação básica. Algumas questões norteadoras são apontadas para iluminar a reflexão: como foi o envolvimento dos alunos durante a aula? As atividades escolhidas foram adequadas aos alunos? Elas foram bem encadeadas? Que estratégias didáticas foram mais eficientes e quais não funcionaram? Por quê? O tempo utilizado para cada atividade foi suficiente para o aprendizado do conteúdo? O ritmo da aula foi mantido entre as atividades desenvolvidas? Como os alunos responderam aos comportamentos e/ou atitudes solicitadas a eles? Como você lidou com a gestão da classe e a gestão dos aprendizados dos alunos? Como você se sentiu? Quais as dificuldades enfrentadas? 
Por quê? Que aprendizados você reconhece que foram adquiridos a partir dessa experiência formativa?

\section{Avaliação}

O estágio finaliza com a socialização das experiências nos Seminários, em que cada grupo destaca aspectos importantes do processo de aprender a ser professor de música em escolas de educação básica. A partir do que eles reconhecem como aprendizados conhecimentos, saberes, atitudes, comportamentos, valores, habilidades - torna-se possível, ao professor orientador, perceber indícios da profissionalidade emergente, observar quais elementos se apresentam mais ou menos estáveis e que pistas se colocam para a continuidade do processo formativo, nos próximos semestres do estágio supervisionado.

Como síntese do processo semestral de estágio, os licenciandos elaboram um relatório final que é entregue ao professor orientador, tendo nos anexos, toda a documentação assinada e carimbada. Os relatórios contêm elementos importantes para avaliar o processo de aprendizagem da docência com foco nas dimensões da profissionalidade - teórica, prática e ética.

No início de cada semestre, os registros escritos do semestre anterior (Pautas de Autoavaliação, diário de campo, relatório final) podem ser retomados para subsidiar discussões acerca de componentes da profissionalidade docente que emergem das experiências anteriores. Pequenos excertos desses relatos podem ser distribuídos e analisados em pequenos grupos, o que possibilita perceber diferentes olhares, escutas e encontros, que se traduzem em formas distintas de perceber e narrar o vivido.

\section{ALGUNS RESULTADOS}

Diante dos limites desse artigo, nessa seção serão analisados alguns dados relativos à observação do espaço escolar e da sala de aula, extraídos dos relatórios de um grupo de três licenciandos. Eles desenvolveram o estágio supervisionado em uma escola estadual de educação básica, na cidade de Ouro Preto (MG), em turmas do $1^{\circ}$ e do $3^{\circ}$ ano do ensino médio, na disciplina Artes. Ao longo das análises, os três licenciandos serão identificados por L1, L2 e L3, e as professoras supervisoras, por P1 e P2. 


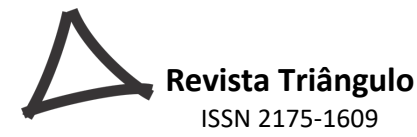

Ao chegar na escola, os licenciandos foram acolhidos por P1, que demonstrou empatia ao aceitar contribuir com a formação dos futuros professores de música, dizendo: "não nego estágio para ninguém, porque eu sei bem como isso é difícil”. Após o aceite, o grupo de estagiários teve a primeira conversa com a professora supervisora a respeito

dos horários, de como seria a participação nas aulas, planejamento das atividades e outras propostas, ou seja, informações que trariam, naquele momento, um melhor entendimento sobre como proceder neste novo ambiente em que estávamos nos inserindo. Nesse mesmo dia, já fomos apresentados a algumas turmas e a professora nos levou para conhecer as dependências da escola e vários profissionais que lá atuam. (Relato L1).

Apesar de bom acolhimento de P1, ela

demonstrou claramente sua insatisfação com o trabalho, e sua desistência em relação aos seus alunos. Ela nos disse de cara que a escola era desorganizada, que as salas de aulas eram terríveis e que, em muitas delas, encontraríamos alunos consumidores de drogas. Não sei qual era a intenção dela ao dizer aquilo, nada positivo! Mas a minha vontade foi de sair correndo e partir para uma escola com "alunos de bem". (Relato L2).

As impressões negativas de P1 sobre a profissão, a escola e os alunos denotam um desencantamento com a docência, o que contribui para a construção de preconceitos pelos licenciandos, antes mesmo de conhecer o espaço escolar ou a sala de aula e os alunos. Como afirma L2, "através dessas informações já construímos o caráter dos nossos futuros alunos: bagunceiros e maconheiros". Ao refletir sobre isso, L2 afirma que "é preciso tomar muito cuidado com o que falamos, principalmente se estamos à frente de um cargo importante que é o de educar". Esse episódio contribui para a reflexão crítica sobre a postura ética do profissional da educação.

Do ponto de vista estrutural, a escola tem dois andares e possui 14 salas de aulas, sendo que as menores ficam localizadas no segundo andar. Além desses espaços, a escola conta com

sala de professores, sala da diretoria, laboratório de informática (sem funcionamento) e laboratório de ciências, sala de recursos multifuncionais para Atendimento Educacional Especializado (AEE), quadra de esportes descoberta, lanchonete, biblioteca, banheiros, sala da secretaria, despensa, almoxarifado, auditório, pátio com uma parte coberta e outra não, e uma área verde lindíssima. As dependências e sanitários da escola não são acessíveis aos portadores de deficiência. (Relatório L3).

Com relação às condições do ambiente, L3 descreve que:

as salas não são bem arejadas, não possuem muita claridade, poucas têm cortinas, duas ou três no máximo, que ficam localizadas no primeiro andar, e que são as maiores salas! A ventilação é péssima, sem ar condicionado e nem todas têm ventilador. $\mathrm{O}$ espaço é mais ou menos organizado, mas é limpo. 


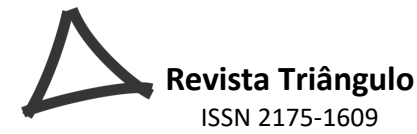

A observação da estrutura permite aos licenciandos perceber outros espaços na escola, para além das salas de aula, que podem ser utilizados para as aulas de música, uma vez que as condições das salas são pouco adequadas. O que se percebe é que os dados corroboram as impressões da P1 relativas as condições físicas da escola, e também permitem problematizar a inclusão e a acessibilidade em escolas públicas de educação básica como direito das pessoas com deficiência.

$\mathrm{Na}$ fase de observação da sala de aula, os licenciandos puderam perceber o funcionamento das aulas e sua relação com o contexto e a profissionalidade de cada professor. Ao observar as aulas de duas professoras, os licenciandos relatam diferentes estilos de ensino, ou seja, formas distintas de organização da gestão da classe e dos aprendizados dos alunos, o que lhes permite perceber opções didáticas mais ou menos eficientes.

De acordo com L2, na sala da P1 havia uma grande falta de comunicação e de estabelecimento de regras: "os alunos eram livres para se comportarem da maneira como bem quisessem; noventa por cento fazia qualquer coisa, menos prestar atenção na aula e, os outros dez por cento, faziam o que lhes era dado, sem ordem”. Refletindo sobre esse aspecto, L2 afirma que: "sem diálogo, não acredito que seja possível conduzir uma boa aula, adolescentes precisam de novidades, de coisas que prendem sua atenção, e não dá para conseguir isso apenas escrevendo coisas no quadro e finalizando com um exercício qualquer".

Por sua vez, L3 relaciona problemas do espaço da sala de aula ao funcionamento da aula - comportamento dos alunos, relações interpessoais (professor aluno; aluno/aluno), além de destacar atitudes de desrespeito e desinteresse. Conforme relata L3, "os alunos e professores não tinham o costume de trabalhar com atividades fora da sala de aula, era sempre a mesma coisa dentro da sala de aula". A esse respeito, L3 argumenta que vê "esse tipo de coisa como uma questão importante a se pensar, a mudança de espaço já é uma novidade para o aluno”. Continuando, L3 relata as seguintes condições das salas de aula:

as salas sem ar condicionado, com espaço insuficiente para o número de alunos existentes vai dificultar bastante o ensino de música; carteiras enfileiradas ocupando muito espaço e dificultando a locomoção de um lado para outro da sala; alunos, em sua maioria, com smartfones e fones de ouvido durante as aulas; alguns até ouvindo música sem fones, rabiscando carteiras e paredes, brincadeiras não condizentes com o ambiente de aula; as carteiras muito próximas umas das outras também contribuem para intensificar as conversas paralelas; alunos sob efeito de drogas e a presença de alunos que são também traficantes, segundo relato da professora; muitos gritos de palavras de baixo calão por parte dos alunos; muitos pedidos de autorização para ir ao banheiro sem a necessidade, mas com a intenção de sair da sala por outros motivos que não dizem respeito à disciplina. Todas estas negatividades, muitas vezes, leva a professora a se exaltar e gritar, o que também não é bom para o ambiente escolar. (Relatório L3). 


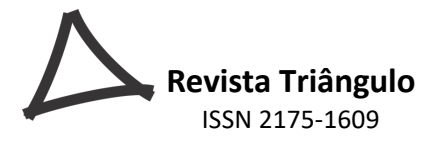

Com relação ao desenvolvimento das aulas da P1, outro importante relato é trazido por

L1:

\begin{abstract}
A rotina da condução destas aulas se resume assim: a professora entra na sala com alguns minutos de atraso devido ao trânsito entre uma sala e outra, atraso de mais uns dez minutos por causa da desordem e indisciplina da turma. Após conseguir controlar um pouco a turma, a professora dá as costas para a turma e copia matéria no quadro durante uns quinze minutos, enquanto os alunos ficam numa indisciplina absurda. Neste momento, só restam vinte minutos para terminar a aula. Ela passa uma folha de caderno como lista de presença entre os alunos para ser assinada, e durante cinco minutos, ela passa entre os alunos carimbando o caderno de quem copiou a matéria passada no quadro, que são poucos alunos. Nos dez ou quinze minutos restantes, ela se dirige à porta no intuito de conter a saída antecipada dos alunos da sala. Neste sentido, o que se observa, é que o tempo efetivo de aula é muito pouco, ou nenhum.
\end{abstract}

Discutindo sobre a forma de gestão da classe, L1 afirma que "no que se refere ao ambiente da sala ser agradável e silencioso, percebi que isso depende muito do professor. Isso porque, as turmas da P1 eram muito bagunçadas e extremamente barulhentas". Essa reflexão vai ao encontro do que afirmam Gauthier at al. (2013, p. 346), que "a ordem pedagógica é construída em parte na interação entre os sujeitos e procede da iniciativa do professor". Continuando, L1 destaca que "a professora não fazia nem questão de falar durante as aulas, porque não conseguia ter a atenção dos alunos. Em geral, ela recorria sempre ao caderno de ocorrência". O que se percebe é que, como as funções pedagógicas são interdependentes, a forma de gestão dos aprendizados por P1 tornava a aula desinteressante e, como consequência, surgiam inúmeros problemas de comportamento dos alunos, o que impossibilitava a gestão da classe pela professora.

Já a P2 tinha "pulso firme, tinha regras estabelecidas dentro da sala de aula". No início da aula,

ela entra em sala e expõe aos alunos o que vai ser trabalhado no dia e dá algum outro recado, se necessário. Depois, ela escreve a matéria no quadro para que os alunos copiem. Enquanto isso, ela permite que os alunos com atraso adentrem à sala sem problemas e sem mesmo ter que pedir permissão para entrar, mas somente até 10 minutos. Após este período é proibida a entrada. Ela permite também que haja uma conversa moderada. Ao terminar de copiar a matéria no quadro, a professora se volta para os alunos para explicar o conteúdo escrito. Neste momento, não é permitido mais conversa e os alunos já sabem disso. Então, ela termina suas explicações e passa uma tarefa, sempre acompanhada de um papel impresso que contem mais conteúdo ou exemplos e fotos sobre o conteúdo. A P2 se apresenta sempre com disposição para melhorar sua aula, levando datashow, som, computador e outros dispositivos que ficam armazenados em outros locais da escola; até mesmo trazendo de casa pertences de propriedade particular, que acaba carregando nas costas durante toda a sua estada na escola, mesmo os objetos sendo pesados. (Relatório L2). 


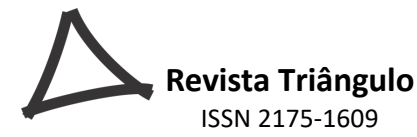

Outras estratégias de gestão da classe são observadas nas aulas da P2, como maior interação entre professor e alunos.

\begin{abstract}
A P2 chega na sala, cumprimenta muito brevemente os alunos e já começa a passar um conteúdo no quadro. Após escrever no quadro, ela pede a atenção dos alunos estralando os dedos. Um dos pontos que eu acho muito interessante sobre a P2 é como ela consegue ser uma professora que impõe respeito e ainda brinca com os alunos, além de ser uma professora que está sempre estimulando os alunos. (Relatório L3).
\end{abstract}

Tomando por base a estrutura ternária da aula - abertura, desenvolvimento e fechamento - apresentada por Gauthier (2003), L1 faz um paralelo entre as formas de gestão dos aprendizados dos alunos:

Com relação à estrutura das aulas, a professora $\mathrm{P} 1$ não fazia uma abertura, ela já ia direto para o desenvolvimento da aula, já começava a aula passando o conteúdo. Já a P2, começava a aula relembrando um conteúdo que ela já tinha trabalhado, e explicava o que seria feito durante a aula e qual era o objetivo do conteúdo. No desenvolvimento da aula, ambas as professoras passavam textos no quadro: a professora P1 copia textos do livro didático indicado pelo governo, e a P2 prefere fazer um pequeno resumo em formato de esquema, usando diversos textos como referências. Para o fechamento da aula, $\mathrm{P} 1$ recolhe a atividade que foi feita em sala ou pede para os alunos entregarem na próxima aula. Já P2 explica o que será feito na próxima aula, recolhe a atividade prática e relembra os alunos sobre a atividade extra que ela trabalha na última semana do mês.

As Pautas de observação do espaço escolar e da sala de aula, construídas a partir dos estudos de Gauthier at al. (2013), proporcionaram aos licenciandos um suporte teórico robusto para analisar a estrutura e funcionamento das aulas, entendendo diferentes estratégias de planejamento, interação e avaliação dos aprendizados. Todos os aspectos identificados nas atividades de observação foram tomados como pistas para a elaboração de intervenções didáticas mais estruturadas, considerando-se as estratégias de gestão da classe e gestão dos aprendizados mais apropriadas ao ensino de música nesse contexto escolar.

\title{
ALGUMAS CONSIDERAÇÕES
}

A formação do professor de música que tem como eixo a construção da profissionalidade permite pensar o processo de profissionalização do ensino de forma mais articulada. Ao desenvolver, simultaneamente, o conhecimento teórico, prático e, a partir da reflexão e da tomada de consciência das escolhas pedagógicas, incorporar o agir ético e responsável do fazer docente, a profissionalidade docente vai se modelando e se fortalecendo a cada nova experiência. Mas, não é por meio de qualquer experiência, mas antes, daquela que possibilita "que algo nos aconteça ou nos toque". 


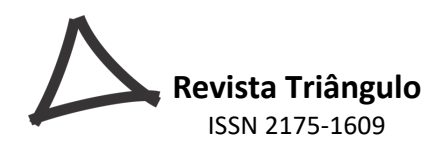

O exercício de "cultivar a arte do encontro" precisa ser desenvolvido no interior dos diferentes espaços curriculares, em que a escuta, o olhar, a percepção de si e do outro sejam alargados e tomados como fundamentais à construção daquilo que é específico na ação docente - a profissionalidade. Ao se deparar com as próprias decisões a respeito da prática que cada um realiza, a dimensão ética é colocada em evidência; ao desenvolver a capacidade de ler o real, a percepção é ampliada e os saberes passam a apoiar a compreensão.

O desenvolvimento do projeto didático de construção da profissionalidade apoiado no referencial teórico e nas Pautas Didáticas potencializou o processo de reflexão, análise, organização e sistematização dos dados coletados. Isso permitiu aos alunos a tomada de consciência sobre a importância da reflexão e do "encontro" no processo de aprendizagem da profissão docente.

\section{REFERÊNCIAS}

ALTET, M. Les compétences de l'enseignant-professionnel: entre savoirs, schèmes d'action et adaptation, le savoir analyser. In: PAQUAY, L. et al. Former des enseignants professionnels: quelles stratégies? Quelles compétences? Bruxelles: De Boeck, 2012.

DEL BEN, L. M. Música nas escolas. Salto para o futuro. Série Educação Musical Escolar, v. Boletim 08, p. 24-33, ANO XXI, Jun. 2011.

FARIAS, I. M. S. et al. Didática e Docência: aprendendo a profissão. Brasília: Liber Livro, 2011.

GAUTHIER, C. et al. Por uma teoria da pedagogia: pesquisas contemporâneas sobre o saber docente. Ijuí: Editora Unijuí, 2013.

GAUTHIER, C.; BISSONNETTE, S.; RICHARD, M. Enseignement explicite et réussite des élèves: la gestion des apprentissages. Québec: Pearson, 2013.

GORZONI, Sílvia de Paula; DAVIS, Cláudia. O conceito de profissionalidade docente nos estudos mais recentes. Cadernos de Pesquisa, v.47, n.166, p.1396-1413, out./dez., 2017. 
NARITA, Flávia Motoyama. Em busca de uma educação musical libertadora: modos pedagógicos identificados em práticas baseadas na aprendizagem informal. Revista da ABEM, Londrina, v.23, n.35, p. 62-75, jul. dez, 2015.

NÓVOA, A. Os professores e o "novo" espaço público da educação. In: NÓVOA, A. (Ed.). Formação de professores e trabalho pedagógico. Lisboa: EDUCA, 2002.

NÚNEZ, Isauro Beltrán; RAMALHO, Betania Leite. A profissionalização da docência: um olhar a partir da representação de professoras do ensino fundamental. Revista Iberoamericana de Educación, vol. 46, n. 9, p. 1-13, 2008.

OLIVEIRA, Zaqueu Vieira; KIKUCHI, Luzia Maya. O laboratório de matemática como espaço de formação de professores. Cadernos de Pesquisa, v.48, n.169, p.802-829, jul./set., 2018.

PIMENTA, S. G.; LIMA, M. S. L. Estágio e docência. São Paulo: Cortez, 2008.

PIRES, Nair. A profissionalidade emergente dos licenciandos em música: conhecimentos profissionais em construção no PIBID música. Tese (Doutorado em Educação) - Faculdade de Educação da Universidade Federal de Minas Gerais. Belo Horizonte, 2015a.

PIRES, Nair. A profissionalidade emergente: a expertise e a ética profissional em construção no Pibid Música. Revista da Abem, Londrina, v.23, n.35, p. 49-61, jul. dez. 2015 b.

SACRISTÁN, J. G. Consciência e acção sobre a prática como libertação profissional dos professores. In: NÓVOA, A. (Ed.). Profissão Professor. Lisboa: Porto Editora, p.61-92, 1995.

SHULMAN, L. S. Those Who Understand: Knowledge Growth in Teaching. Educational Researcher, v. 15, n. 2, p. 4-14, February 1986.

SILVA, Rafael Rodrigues. Gestão de sala de aula na educação musical escolar. Revista da ABEM, Londrina, v.21, n.31, p. 63-76, jul. dez, 2013. 
SWANWICK, K. A basis for music education. London: Routledge, 1979.

TARDIF, M. Saberes docentes e formação profissional. Petrópolis: Editora Vozes, 2011.

ZABALA, A. A prática educativa: como ensinar. Porto Alegre: Artmed, 2010.

ZABALZA, M. O estágio e as práticas em contextos profissionais na formação universitária. São Paulo: Cortez, 2014. 